\title{
Prolactin Serum Levels and Alcohol Craving - An Analysis Using Lesch's Typology
}

\author{
Thomas Hillemacher Kristina Bayerlein Julia Wilhelm Helge Frieling \\ Wolfgang Sperling Johannes Kornhuber Stefan Bleich \\ Department of Psychiatry and Psychotherapy, University of Erlangen-Nuremberg, Erlangen, Germany
}

\section{Key Words}

Alcohol craving · Prolactin · Lesch's typology · Anxiety

\begin{abstract}
Background: Prolactin secretion is closely connected to dopaminergic transmission that is known to play a crucial role in mediating reinforcement and craving in alcoholism. Objectives: The study was performed to analyze the association between prolactin serum levels and alcohol craving during withdrawal differentiating alcoholdependent patients using Lesch's typology. Methods: We assessed 115 male patients with the Obsessive Compulsive Drinking Scale at early alcohol withdrawal. In addition, serum was obtained to measure prolactin concentration and the patients were classified according to Lesch's typology into one of four subgroups. Results: Correlation analysis showed a significant association between prolactin serum levels and the extent of craving in Lesch's type 2 patients ( $r=0.32, p=0.015 ; n=57)$; however, no association was found for any other subgroup. The results were confirmed comparing patients with low and high craving (Mann-Whitney $U$ test: $Z$ = -2.805, $p=0.005)$. Conclusions: In patients of Lesch's type 2, who are characterized to suffer from anxiety and to use alcohol because of its anxiolytic effects, prolactin is associated with craving during early alcohol withdrawal.
\end{abstract}

Copyright (C) 2006 S. Karger AG, Basel

\section{KARGER}

Fax +4161306 1234 E-Mailkarger@karger.ch www.karger.com (c) 2006 S. Karger AG, Basel 0302-282X/06/0533-0133\$23.50/0

Accessible online at: www.karger.com/nps

\section{Introduction}

Research on neurobiological mechanisms in alcohol dependency has shown that the dopaminergic reward system plays a crucial role in reinforcement and craving [13]. Recent studies have proposed that downregulated central dopaminergic receptors normalize during detoxification [4]. Apart from the important role of dopamine in central neurotransmission, it is known to act as prolactin inhibiting factor [5], which leads to a possible association between dopaminergic function (mediated mainly via dopamine $\mathrm{D}_{2}$ receptors), prolactin levels and psychological changes during alcohol dependence such as craving. In a recent study, we described an association between individual changes of prolactin serum levels during detoxification and craving in female patients, while we found no association in male patients [6].

The aim of this study was to analyze a possible association between prolactin serum levels and craving using a well-established classification of alcohol dependence. Numerous studies in alcohol research point towards the importance of classifying patients into subgroups, while different classifications have been proposed in the past. The Lesch typology has been used in various investigations [7-10] and takes social, mental and somatic factors into account $[11,12]$. The typology distinguishes four different subtypes: type 1 patients (model of 'allergy') are characterized to suffer from heavy alcohol withdrawals 
Table 1. Demographic characteristics of the study population (mean $\pm \mathrm{SD}$ )

\begin{tabular}{lcccc}
\hline & $\begin{array}{l}\text { Lesch's type 1 } \\
(\mathrm{n}=27)\end{array}$ & $\begin{array}{l}\text { Lesch's type 2 } \\
(\mathrm{n}=57)\end{array}$ & $\begin{array}{l}\text { Lesch's type 3 } \\
(\mathrm{n}=19)\end{array}$ & $\begin{array}{l}\text { Lesch's type 4 } \\
(\mathrm{n}=12)\end{array}$ \\
\hline OCDS total $^{1}$ & $17.3 \pm 7.3$ & $21.2 \pm 7.4$ & $21.4 \pm 8.0$ & $24.8 \pm 7.1$ \\
Prolactin $^{1}, \mathrm{ng} / \mathrm{ml}$ & $18.6 \pm 12.8$ & $13.6 \pm 9.0$ & $13.1 \pm 7.8$ & $10.1 \pm 3.5$ \\
Age, years $_{\text {Years of drinking }}$ & $44.3 \pm 8.9$ & $44.4 \pm 9.1$ & $43.7 \pm 8.4$ & $39.7 \pm 8.5$ \\
Daily intake, g & $214.5 \pm 10.2$ & $19.9 \pm 10.1$ & $21.7 \pm 10.1$ & $19.7 \pm 10.1$ \\
Lifetime drinking, $\mathrm{kg}$ & $1,476 \pm 1,094$ & $259.3 \pm 182.8$ & $283.4 \pm 213.2$ & $263.2 \pm 127.2$ \\
\hline
\end{tabular}

${ }^{1}$ Significant differences between the different types of Lesch's typology, tested with the Kruskal-Wallis test for independent samples $(\mathrm{p}<0.05)$. and tend to use alcohol to weaken withdrawal symptoms. Patients of type 2 (model of anxiety or conflict) use alcohol as self-medication because of anxiolytic effects. The main characteristic of type 3 patients (alcohol as an antidepressant) is an underlying affective disorder as the origin of alcohol abuse. Type 4 patients (alcohol as adaptation) show premorbid cerebral defects, behavioral disorders and a high social burden.

\section{Materials and Methods}

The present study was part of a larger prospective investigation (Franconian Alcoholism Research Studies) [13-15] and was approved by the Ethics Committee of the Medical Faculty, University of Erlangen-Nuremberg, Germany. Written, informed consent was obtained from all patients who all met criteria for alcohol dependency according to ICD-10 and DSM-IV. One hundred and nineteen men and 26 women participated in the study. The female patients were not included in the present analysis due to the small number for subgroup analysis (Lesch's typology). In 4 male patients, data were not recorded completely enough to classify the patients referring to Lesch's typology, which reduced the number of patients for analysis to 115 . All patients underwent withdrawal treatment after admission using clomethiazole and carbamazepine. Patients with concomitant psychiatric diseases and other substance abuse apart from alcohol or nicotine dependence, known dysfunction of the hypothalamic-pituitary-adrenal axis or thyroid diseases were not included in the study. Abstinence during hospitalization was monitored by carbohydrate-deficient transferrin, continuous urine and breath analysis. We obtained serum for prolactin analysis at the same time (8:00 a.m.) on day 0 or day 1 . Blood samples were centrifuged directly after blood withdrawal and stored continuously at $-80^{\circ} \mathrm{C}$ until assaying Prolactin concentrations were measured using the Abbott AxSYM (cat. No. 7A62-22, Abbott Park, Ill., USA) based on microparticle enzyme immunoassay technology. Additionally, blood alcohol concentration was measured at admission.

The extent of craving during withdrawal treatment was assessed with the Obsessive Compulsive Drinking Scale (OCDS) [16, 17] on the day of hospitalization. The OCDS is a well-validated instrument that assesses craving more constantly and more stably than for example a visual analogue scale. Patients were classified according to Lesch's typology into one of four subgroups. Furthermore, sociodemographic data [educational status, known somatic illnesses, preceding withdrawals, daily intake of alcohol (in grams), the period of drinking (in years) and lifetime drinking (daily intake in kilograms $\times 365$ days $\times$ years of drinking)] were taken in a semistructured interview by a trained observer (K.B.).

Descriptive results are given as mean (SD) and median. To compare patients with low and high craving, we applied a previously described median split division of the OCDS [18]. For all statistical tests, we assessed a significance level of $\alpha<0.05$. The statistical analysis was performed using SPSS ${ }^{\mathrm{TM}}$ for Windows version 11.5 (SPSS Inc., Chicago, Ill., USA).

\section{Results}

The sociodemographic characteristics of the four groups of Lesch's typology (differences between the groups were tested with the Kruskal-Wallis test) are shown in table 1. Prolactin serum levels were highest in patients of Lesch's type 1 while Lesch's type 4 patients showed the most elevated craving scores. Spearman correlation analysis revealed a significant association between prolactin serum levels and the OCDS for patients of Lesch's type 2 $(r=0.32, p=0.015 ; n=57)$. None of the other subgroups of Lesch's typology (type 1: $r=0.18, p=0.359, n=27$; type 3: $r=0.04, p=0.883, n=19$; type $4: r=-0.02, p=$ $0.939, \mathrm{n}=12)$ nor the whole study population $(\mathrm{r}=0.13$, $\mathrm{p}=0.174, \mathrm{n}=115$ ) showed significant results with the OCDS in the correlation analysis.

Comparing patients with low and high craving (using the above-mentioned median split division of the OCDS), we found a significant difference regarding prolactin serum levels in the group of patients with Lesch's type 2 (Mann-Whitney U test: $\mathrm{Z}=-2.805, \mathrm{p}=0.005, \mathrm{n}=57$; fig. 1 ); however, no difference was found for any of the other subtypes. 
Receiver operating characteristic curves also showed significant predictive qualities for craving in Lesch's type 2 patients (area under the curve $=0.717,95 \%$ confidence interval $=0.577-0.857, \mathrm{p}=0.005$; fig. 2 ).

\section{Discussion}

To our knowledge, this is the first study investigating prolactin levels in alcoholic patients classified according to Lesch's typology. As a main result, we observed a significant association between the extent of alcohol craving and prolactin levels in patients with alcohol dependency according to Lesch's type 2. These patients tend to suffer from anxiety disorders and use alcohol consumption especially for its anxiolytic effect. Prolactin has been suggested to be associated with anxiety and panic attacks in previous studies $[19,20]$. Also, elevated baseline prolactin has been reported in patients with panic disorders [21].

Long-term alcohol consumption is known to lead to a chronic stimulation of dopaminergic receptors [22, 23]. We suggest that the association between elevated prolactin levels and craving during alcohol withdrawal may be the result of a reduction of mesolimbic dopaminergic activity that has been associated with dysphoric emotional states and craving during alcohol withdrawal [24, 25]. The present results link two different dopaminergic pathways, the tuberoinfundibular and the mesocorticolimbic dopamine system. The tuberoinfundibular system has not been discussed to be relevant to alcohol craving up to now. However, recent research has shown evidence that both the tuberoinfundibular and the mesocorticolimbic system may be regulated by $\mathrm{D}_{2}$ receptors, which have been associated with cognitive and affective functions of the mesocorticolimbic system [26], prolactin secretion, and activity of the tuberoinfundibular dopamine neurons [27]. Hence, our results suggest an association of both dopaminergic pathways in the pathophysiology of alcohol craving.

Furthermore, glutamatergic neurotransmission, which is also supposed to play an important role in withdrawal craving [28, 29], has been linked with prolactin secretion [30-32]. The present study suffers from the following limitations: because of the small number of patients in the groups 1, 3 and 4 of Lesch's typology, we cannot generally rule out an association between craving and prolactin in these patients. On the other hand, the whole male population showed no association between both variables and also the correlation coefficient was low in type 1,3

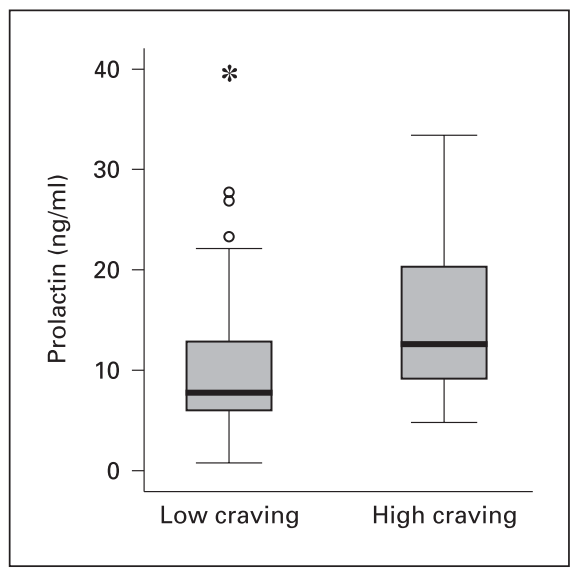

Fig. 1. Box plot comparing patients of Lesch's type 2 with high and low craving in early withdrawal after using a median split division of the OCDS. Statistical significance was tested with Mann-Whitney $U$ test: $\mathrm{Z}=-2.805, \mathrm{p}=0.005, \mathrm{n}=57$.

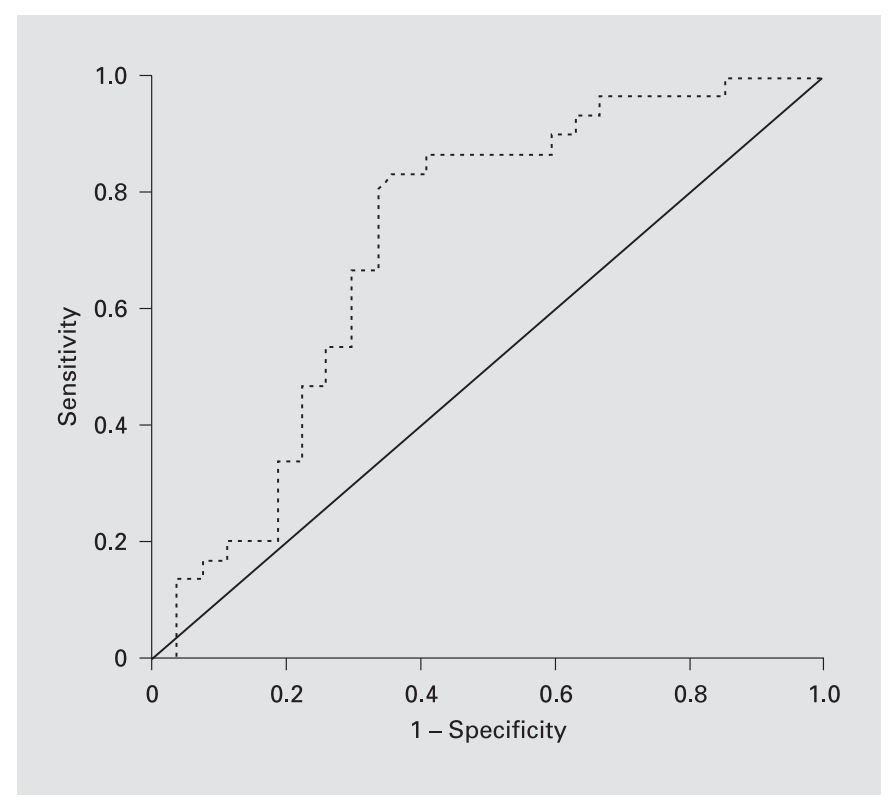

Fig. 2. Receiver operating characteristic curve for Lesch's type 2 patients in early withdrawal; area under the curve $=0.717,95 \%$ confidence interval $=0.577-0.857, \mathrm{p}=0.005$.

and 4 patients, which makes a relevant association in these groups improbable. Another important limitation is the lack of measuring thyrotropin-releasing hormone, which is known to influence the release of prolactin [33]. 
In conclusion, we found first evidence for an association between prolactin secretion and craving in a specific subgroup of patients. Further research is necessary to elucidate the pathophysiological mechanisms linking prolactin and craving in alcoholism and to investigate clinical implications for a subgroup-specific therapy.

\section{Acknowledgements}

We gratefully acknowledge the excellent technical assistance of Dr. Georg Beck and the support by a grant (T.H., S.B.) from the ELAN fund ('Erlanger Leistungsbezogene Anschubfinanzierung und Nachwuchsförderung'), Friedrich-Alexander University of Erlangen-Nuremberg, Germany. Also we would like to thank Dr. Brigitte Mugele, Klinik für Sucht und Psychotherapeutische Medizin, Klinikum am Europakanal, Erlangen, Germany, for her excellent support in recruiting patients.

\section{References}

1 Wise RA: The neurobiology of craving: implications for the understanding and treatment of addiction. J Abnorm Psychol 1988;97:118132.

2 Tupala E, Tiihonen J: Dopamine and alcoholism: neurobiological basis of ethanol abuse. Prog Neuropsychopharmacol Biol Psychiatry 2004;28:1221-1247.

3 Bowirrat A, Oscar-Berman M: Relationship between dopaminergic neurotransmission, alcoholism, and reward deficiency syndrome. Am J Med Genet B Neuropsychiatr Genet 2005; 132:29-37.

4 Markianos M, Moussas G, Lykouras L, Hatzimanolis J: Dopamine receptor responsivity in alcoholic patients before and after detoxification. Drug Alcohol Depend 2000;57:261-265.

5 Ben-Jonathan N, Hnasko R: Dopamine as a prolactin (PRL) inhibitor. Endocr Rev 2001; 22:724-763.

6 Hillemacher T, Bayerlein K, Wilhelm J, Reulbach U, Frieling H, Bönsch D, Kornhuber J, Bleich S: Alteration of prolactin serum levels during alcohol withdrawal correlates with craving in female patients. Addict Biol 2005; 10:337-343.

7 Bleich S, Bayerlein K, Reulbach U, Hillemacher T, Bönsch D, Mugele B, Kornhuber J, Sperling W: Homocysteine levels in patients classified according to Lesch's typology. Alcohol Alcohol 2004;39:493-498.

8 Lesch OM, Riegler A, Gutierrez K, Hertling I, Ramskogler K, Semler B, Zoghlami A, Benda N, Walter H: The European acamprosate trials: conclusions for research and therapy. $\mathrm{J}$ Biomed Sci 2001;8:89-95.

9 Kiefer F, Helwig H, Tarnaske T, Otte C, Jahn $\mathrm{H}$, Wiedemann K: Pharmacological relapse prevention of alcoholism: clinical predictors of outcome. Eur Addict Res 2005;11:83-91.

10 Hillemacher T, Bayerlein K, Wilhelm J, Bönsch D, Poleo D, Sperling W, Kornhuber J, Bleich S: Recurrent detoxifications are associated with craving in patients classified as type 1 according to Lesch's typology. Alcohol Alcohol 2006;41:66-69.

11 Lesch OM, Walter H: Subtypes of alcoholism and their role in therapy. Alcohol Alcohol 1996;31(suppl 1):63-67.

12 Lesch OM, Kefer J, Lentner S, Mader R, Marx B, Musalek M, Nimmerrichter A, Preinsberger $\mathrm{H}$, Puchinger H, Rustembegovic A, et al: Diag- nosis of chronic alcoholism - Classificatory problems. Psychopathology 1990;23:88-96.

13 Hillemacher $\mathrm{T}$, Bayerlein K, Reulbach U, Sperling W, Wilhelm J, Mugele B, Kraus T, Bönsch D, Kornhuber J, Bleich S: Influence of beer, wine and spirits consumption on craving. Addict Biol 2005; 10:181-186.

14 Hillemacher T, Reulbach U, Bayerlein K, Wilhelm J, Bönsch D, Sperling W, Kornhuber J, Bleich S: Plasma homocysteine concentrations do not influence craving in alcohol withdrawal. Alcohol 2004;34:211-215.

15 Bleich S, Carl M, Bayerlein K, Reulbach U, Biermann T, Hillemacher T, Bönsch D, Kornhuber J: Evidence of increased homocysteine levels in alcoholism: the Franconian Alcoholism Research Studies (FARS). Alcohol Clin Exp Res 2005;29:334-336.

16 Anton RF, Moak DH, Latham P: The Obsessive Compulsive Drinking Scale: a self-rated instrument for the quantification of thoughts about alcohol and drinking behavior. Alcohol Clin Exp Res 1995;19:92-99.

17 Anton RF, Moak DH, Latham PK: The obsessive compulsive drinking scale: a new method of assessing outcome in alcoholism treatment studies. Arch Gen Psychiatry 1996;53:225231.

18 Ingjaldsson JT, Thayer JF, Laberg JC: Craving for alcohol and pre-attentive processing of alcohol stimuli. Int J Psychophysiol 2003;49: 29-39.

19 Apostolopoulos M, Judd FK, Burrows GD, Norman TR: Prolactin response to dl-fenfluramine in panic disorder. Psychoneuroendocrinology 1993; 18:337-342.

20 Otte C, Kellner M, Arlt J, Jahn H, Holsboer F, Wiedemann K: Prolactin but not ACTH increases during sodium lactate-induced panic attacks. Psychiatry Res 2002;109:201-205.

21 Hollander E, Liebowitz MR, Cohen B, Gorman JM, Fyer AJ, Papp LA, Klein DF: Prolactin and sodium lactate-induced panic. Psychiatry Res 1989;28:181-191.

22 Gessa GL, Muntoni F, Collu M, Vargiu L, Mereu G: Low doses of ethanol activate dopaminergic neurons in the ventral tegmental area. Brain Res 1985;348:201-203.

23 Imperato A, Di Chiara G: Preferential stimulation of dopamine release in the nucleus accumbens of freely moving rats by ethanol. J Pharmacol Exp Ther 1986;239:219-228.
24 Diana M, Pistis M, Carboni S, Gessa GL, Rossetti ZL: Profound decrement of mesolimbic dopaminergic neuronal activity during ethanol withdrawal syndrome in rats: electrophysiological and biochemical evidence. Proc Natl Acad Sci USA 1993;90:7966-7969.

25 Diana M, Pistis M, Muntoni A, Gessa G: Mesolimbic dopaminergic reduction outlasts ethanol withdrawal syndrome: evidence of protracted abstinence. Neuroscience 1996;71: 411-415.

26 Larson ER, Ariano MA: $\mathrm{D}_{3}$ and $\mathrm{D}_{2}$ dopamine receptors: visualization of cellular expression patterns in motor and limbic structures. Synapse 1995;20:325-337

27 Durham RA, Eaton MJ, Moore KE, Lookingland KJ: Effects of selective activation of dopamine $\mathrm{D}_{2}$ and $\mathrm{D}_{3}$ receptors on prolactin secretion and the activity of tuberoinfundibular dopamine neurons. Eur J Pharmacol 1997; $335: 37-42$

28 Kiefer F, Jahn H, Koester A, Montkowski A, Reinscheid RK, Wiedemann K: Involvement of NMDA receptors in alcohol-mediated behavior: mice with reduced affinity of the NMDA R1 glycine binding site display an attenuated sensitivity to ethanol. Biol Psychiatry 2003;53:345-351.

29 De Witte P: Imbalance between neuroexcitatory and neuroinhibitory amino acids causes craving for ethanol. Addict Behav 2004;29: 1325-1339.

30 Bregonzio C, Moreno GN, Cabrera RJ, Donoso AO: NMDA receptors in the medial zona incerta stimulate luteinizing hormone and prolactin release. Cell Mol Neurobiol 2004;24: 331-342.

31 Bregonzio C, Navarro CE, Donoso AO: NMDA receptor antagonists block stress-induced prolactin release in female rats at estrus. Eur $\mathbf{J}$ Pharmacol 1998;350:259-265.

32 Pinilla L, Gonzalez D, Tena-Sempere M, Aguilar R, Aguilar E: Effects of N-methyl- $D$-aspartate and kainic acid on prolactin secretion in prepubertal female rats. Eur J Endocrinol 1996; 135:464-468

33 Tashjian AJ, Barowsky N, Jensen D: Thyrotropin releasing hormone: direct evidence for stimulation of prolactin production by pituitary cells in culture. Biochem Biophys Res Commun 1971;43:516-523.

Hillemacher/Bayerlein/Wilhelm/Frieling/ Sperling/Kornhuber/Bleich 